\title{
A MICROEMPRESA NA CONSTITUCUIÇÃO FEDERAL: ANÁLISE DA RELEVÂNCIA DOS PEQUENOS NEGÓCIOS À LUZ DE CEM ANOS DE SOLIDÃO, DE GABRIEL GARCÍA MÁRQUES
}

\section{THE MICROENTERPRISE IN THE FEDERAL CONSTITUTION: ANALYSIS \\ OF THE RELEVANCE OF SMALL BUSINESSES IN THE LIGHT OF CEM YEARS OF SOLIDÃO, BY GABRIEL GARCÍA MÁRQUES}

\author{
${ }^{1}$ Bruna Ramos Marinho \\ ${ }^{2}$ Daniela Ramos Marinho Gomes
}

\section{RESUMO}

Este trabalho busca apresentar as razões esposadas na Constituição Federal que justificam o tratamento diferenciado conferido aos pequenos empreendimentos. Para tanto, vale-se da intersecção do Direito e literatura para abstrair os sentidos produzidos na realidade, exercício que requer ao jurista uma habilidade de ler o mundo sob várias perspectivas. A leitura escolhida foi a do livro "Cem anos de solidão", de Gabriel Garcia Marques, figurando a chegada da Companhia das Bananeiras em Macondo como mote para a reflexão quanto à função social das microempresas no cenário brasileiro que, de tão relevante, foi alçada à condição de princípio da ordem econômica Constitucional.

Palavras-Chave: Microempresa, Constituição Federal, Arte e Literatura

\begin{abstract}
This paper seeks to present the reasons espoused in the Federal Constitution that justify the differential treatment given to small enterprises. To do so, it uses the intersection of law and literature to abstract the senses produced in reality, an exercise that requires the jurist an ability to read the world from various perspectives. The literature chosen was Gabriel Garcia Marques' book Cem anos de solão, which included the arrival of Company of banana trees in Macondo as a reflection on the social function of microenterprises in the Brazilian scenario, which was so relevant to Condition of principle of the Constitutional economic order.
\end{abstract}

Key Words: Microenterprise, Federal Constitution, Art and Literature

\footnotetext{
${ }^{1}$ Doutora em Educação pela Universidade Estadual de São Paulo - UNESP, São Paulo (Brasil). Professora pelo Instituto Federal de Roraima - IFRR, Roraima (Brasil) E-mail: bruna.marinho@ifrr.edu

${ }^{2}$ Mestre em Direito Negocial pela Universidade Estadual de Londrina - UEL, Paraná (Brasil). Professora do curso de Direito pelo Centro Universitário Eurípides de Marília - UNIVEM, São Paulo (Brasil). E-mail: danielaramosmarinho@yahoo.com.br
} 


\section{INTRODUÇÃO}

Nas últimas décadas deflagraram-se diversas discussões envolvendo a relevância das pequenas e médias empresas e a sua relação com o desenvolvimento econômico e social. Surgem, em decorrência dessa constatação, normas com escopo de promover um tratamento diferenciado a este segmento empresarial com fincas a estimular seu desenvolvimento e permanência no mercado.

Assim, este trabalho tem como desiderato apresentar as razões esposadas na ordem econômica constitucional que justificam e estimulam o tratamento diferenciado a ser conferido aos pequenos empreendimentos. Para tanto, vale-se da intersecção da arte e literatura para ampliar a percepção do objeto estudado, pois, no mundo jurídico, interpretar a realidade implica abstrair os sentidos produzidos a partir de um determinado contexto, exercício que requer ao jurista uma habilidade de ler o mundo sob várias perspectivas.

$\mathrm{Na}$ verdade, a interseção da literatura com o direito permite analisar as diversas situações do dia a dia e interpretá-las de forma mais ampla porque se consegue, a partir da leitura, compreendê-las histórica, econômica e socialmente dentro de um determinado contexto.

Com este recorte metodológico, e a fim de explorar o objeto deste trabalho, buscase, a partir do episódio da chegada da Companhia das Bananeiras em Macondo, demonstrar a função social das microempresas no cenário brasileiro. $E$ isto se faz necessário porque, como em Macondo, costuma-se atrelar o progresso de uma região apenas à presença dos grandes empreendimentos, quando, na verdade, as estatísticas revelam que as microempresas representam quase $90 \%$ (noventa por cento) dos postos de trabalho.

Tamanha é sua contribuição com o desenvolvimento que, nas últimas décadas, deflagraram-se diversas discussões envolvendo a relevância das pequenas e médias empresas. Surgem, em decorrência dessa constatação, normas com escopo de promover um tratamento diferenciado a este segmento empresarial com fincas a estimular seu desenvolvimento e permanência no mercado.

Utilizando o trágico desfecho de Cem anos de Solidão que, em sua narrativa aponta a matança de centenas de pessoas após o protesto que se instalou com a chegada 
da Companhia das Bananeiras, o trabalho aborda a importância dos pequenos empreendimentos no Brasil, demonstrando que a preservação deste segmento constitui primado da ordem econômica, desenhada na Constituição Federal de 1988.

Com o propósito em menção, este trabalho inicia esclarecendo o conceito de microempresa à luz da legislação e outros órgãos que a definem para fins de concessão de incentivos. Enfatiza, a partir da literatura disponível e das estatísticas, o termo função social, condicionando-o ao papel que é exercido pelo pequenos negócios, quando da valiosa oportunidade de empregos.

Num segundo momento, o trabalho volta-se para os paradigmas constitucionais estampados na Carta de 1988, cujo conteúdo constitucional possibilitou, no capítulo que trata da Ordem econômica, uma previsão específica que impõe tratamento favorecido para as microempresas brasileiras.

Finalizando, deflagra-se uma reflexão sobre a importância e a relevância de se promover interseções entre literatura e o direito para, em seguida, tecer considerações e fazer as relações sobre o notório romance de Gabriel Garcia Marques, intitulado Cem anos de solidão, com enfoque no desfecho do estabelecimento da Companhia Americana de Bananeiras em Macondo para, daí, extrair a reflexão quanto à importância dos pequenos negócios no Brasil.

A pesquisa se deu de forma exploratória com análise bibliográfica a partir de coleta de dados em material científico e informativo atualizado sobre o assunto abordado.

\section{MICROEMPRESA - PARTE CONCEITUAL}

Toda vez que uma grande empresa chega à determinada cidade acaba por despertar notoriedade da mídia. Eventual encerramento ou outra circunstância adversa também ganha destaque. Associa-se o crescimento e desenvolvimento apenas aos grandes empreendimentos, olvidando-se, muitas vezes dos efeitos nefastos que estes podem trazer, como no caso da Companhia das Bananeiras - relatada no livro que será abordado em tópico oportuno, que, no lugar de desenvolvimento, trouxe revolta e mortes. 
Assim é que este trabalho volve-se para a relevância dos pequenos empreendimentos que, ao contrário dos grandes, podem trazer desenvolvimento e dignidade, quando da franca oportunidade de geração de empregos. Para tanto, faz-se necessário apresentar o que se concebe como microempresa.

Destarte, embora não aponte um conceito hermético sobre o termo, Montaño (1999, p.13), explica que a definição de microempresa envolve três aspectos fundamentais, a saber: a dimensão, a complexidade e a formalização.

\begin{abstract}
A dimensão de uma empresa é definida a partir dos custos de produção, do volume de produção e de comercialização, do seu capital fixo e capital de giro, do mercado que atende, do valor do seu lucro, entre outras características. Na pequena empresa, todos os elementos citados acima têm uma dimensão reduzida. A ME e a EPP empregam poucos funcionários, e os níveis de produção e comercialização são baixos. A complexidade de uma empresa envolve sua centralização, estratificação e divisão técnica do trabalho. A centralização é o grau de concentração da autoridade dentro da empresa. Nas pequenas empresas, devido à pequena quantidade de membros, geralmente observa-se uma elevada concentração do poder em seus proprietários. Consequientemente, conclui-se que nas pequenas empresas há baixa estratificação, ou seja, a divisão política do trabalho é pouco complexa. Prevalece nas microempresas basicamente dois estratos: os proprietários na direção empresarial e seus empregados na área produtiva. A divisão técnica do trabalho também é muito simplificada. Há pouca divisão de tarefas, e o trabalhador acompanha o produto desde sua fase inicial de produção até a etapa final.
\end{abstract}

No Brasil identificam-se pelo menos três critérios para classificação das empresas, adotados por instituições oficiais e/ou bancos de investimento e fomento:

I - Segundo o número de empregados. É o desenvolvido pelo Instituto Brasileiro de Geografia e Estatística (IBGE) e pelo Serviço Brasileiro de Apoio às Micro e Pequenas Empresas (SEBRAE), empregado de acordo com a quantidade de pessoas que trabalham nessas empresas. Assim, é considerada microempresa aquela que emprega até nove pessoas no ramo de atividade de comércio e serviços e até dezenove pessoas na indústria.

II - Segundo a Receita Operacional Bruta Anual: é utilizado pelas Instituições de apoio creditício como o BNDS Banco Nacional de Desenvolvimento Econômico e Social -, sendo assim considerada microempresa a que tiver receita bruta anual de até $\mathrm{R} \$ 1.200 .000,00$ (um milhão e duzentos mil reais). 
III- Segundo o Faturamento Bruto Anual: é o que fixa como parâmetro o volume monetário ou econômico da empresa. Esta classificação é utilizada pelas leis federais e estaduais para fins de tributação, considerando os limites de faturamento e seu enquadramento como micro e pequena empresa. É, inclusive, o critério aplicado pela Complementar 123/2003.

Grazziotin (2004, p. 24), concebe a pequena empresa como aquela cujo proprietário empenha direta e decisivamente a sua força de trabalho com reduzido quadro de pessoal. Possui pouco capital e baixa renda bruta com relação ao setor onde opera, e não faz parte de grupo econômico ou esteja interligado com outro empregador.

Observa-se que existem diversos parâmetros para definir e classificar microempresas, os quais são desenvolvimentos para enquadramento com o intuito de usufruir dos benefícios da lei. O critério mais aceito é aquele utilizado com base nas receitas auferidas. Atualmente, é considerada microempresa a empresa cujo faturamento não ultrapassa $R \$ 360$ mil e empresa de pequeno porte a que possui faturamento até $R \$$ 3,6 milhões.

\section{3- FUNÇÃO SOCIAL DA MICROEMPRESA E SUA PROTEÇÃO CONSTITUCIONAL A PARTIR DA CARTA DE 1988.}

Escrevendo sobre a importância da empresa, Comparato (1990, p.3) afirmou que se trata de uma "instituição social que, pela sua influência, dinamismo e poder de transformação, serve como elemento explicativo e definidor da civilização contemporânea".

Toda empresa, seja ela considerada grande ou pequena para os padrões de seu mercado, pode e deve exercer função social. Entretanto, considerando que para este trabalho a função social é entendida como o dever dos meios de produção de serem empregados de forma a dar a melhor destinação sob o ponto de vista dos interesses sociais, como a dignificação do homem, o desenvolvimento nacional, a proteção do Estado e a erradicação da pobreza e das desigualdades, tem-se que esta função é melhor dimensionada quando se trata das microempresas. 
Parte-se da premissa de que, apesar de organizar os meios de produção para a finalidade de lucro, é possível que o segmento empresarial desenvolva uma função social.

É neste contexto que se insere as pequenas empresas porquanto desenvolvem papel de primazia na economia nacional na medida em que absorvem boa parte da mãode-obra do país. Não obstante, representam uma das formas de resistência da população à crescente concentração de riquezas que acaba por aumentar o distanciamento entre as diferentes classes sociais.

Ao apresentar um panorama sobre a microempresa, a pesquisadora Bonfim (2007. p. 5) declara que a sociedade desconhece o potencial escondido por trás do mundo das micros e pequenas empresas e a força que este segmento possui para a economia brasileira, pois prevalece a imagem do pequeno e frágil negócio, de faturamento quase inexpressivo e que emprega geralmente membros da família.

O Instituto Brasileiro de Geografia e Pesquisa - IBGE apresentou dados indicando que do total de empresas existentes, 98,3\% são microempresas ou empresas de pequeno porte, sendo responsáveis por 52,8\% dos empregos disponíveis (ESTATÍSTICAS..., 2014). Estes dados estão a confirmar que os pequenos negócios exercem uma função que se sobrepõe à lógica do lucro.

Conforme as palavras do professor Carlos O. Quandt (2004), as pequenas e médias empresas possuem um grande potencial para acelerar o crescimento econômico, ampliar sua participação nas exportações e promover um padrão de desenvolvimento mais desconcentrado e equitativo nas regiões menos desenvolvidas.

Sobre isto D‘Arcanchy (2008, p. 63,) assim escreveu:

As microempresas (ME) e as empresas de pequeno porte (EPP), em nosso país, têm sua origem, via de regra, em trabalhadores excluídos do mercado de trabalho, que entram no setor de serviços, ou de produção em pequena escala, com mínima tecnologia e pouca formalidade de atividades administrativas.

O jurista Alvim (1998) discorrendo sobre a atual "sociedade do conhecimento", expõe um atributo essencial às microempresas e empresas de pequeno porte, qual seja, ter capacidade de reagir rapidamente neste novo contexto de mudanças constantes. Prossegue afirmando que, dentre as contribuições trazidas pelas microempresas e 
empresas de pequeno porte, destacam-se a presença em diferentes cadeias produtivas, na forma de fornecedores terceirizados e quarteirizados de grandes empreendimentos produtores de bens intermediários e finais, além de atuar como fornecedores de pequenos lotes em nichos de mercado ou em mercados especializados.

Nos últimos anos, em virtude da crise econômica que assola o Brasil, diversos postos de trabalho vêm se fechando; propaga-se a concepção de que a salvação para quem busca emprego tem sido as empresas menores, que absorvem a massa desempregada.

Isto intensifica o argumento de que o segmento dos pequenos empresários, de fato, desempenha em sua gênese a função social esperada pelo ordenamento jurídico brasileiro: é por tal razão que a microempresa ganhou destaque na Constituição Federal de 1988, sendo alçada à condição de princípio da Ordem Econômica.

Por falar em Constituição, há de se mencionar que, ao abordar o paradigma do Estado Democrático de Direito, Gomes ensina que a interpretação e construção da norma constitucional deve ser aquela que:

[...] dignifica a pessoa humana, vista como fundamento maior do referido paradigma estatal, instituído para compor um modo de vida coerente com a natureza, necessidades e condição do ser humano. Por isso, há de se compreender que os objetivos da República, positivados no art. $3^{\circ}$ da Constituição, configuram uma teleologia que tem por meta final a salvaguarda da dignidadereconhecida em cada indivíduo, o qual, no âmbito da democracia é visto como pessoa. É isso que justifica a defesa e a concretização dos direitos fundamentaisem todas as suas dimensões. E é esta também a razão maior para a existência do próprio Estado (GOMES, 2008, p. 315).

Na verdade, um Estado não pode ser considerado democrático se não desenvolver mecanismos que garantam o pleno exercício da cidadania, ou seja, se não fornecer, no plano fático, reais condições para a efetividade da inclusão social. É dizer que a democracia não pode ser analisada no âmbito estritamente teórico, abstrato, em que não se toma o ser humano enquanto pessoa, pois "sem levar em consideração as 'condições' e a situação em que a democracia nasce e se desenvolve, dificilmente poderíamos refletir sobre o tipo de regime sócio-político que vem se construindo nos países da América Latina nestes últimos anos" (VITULO, 2006, p. 355). 
No que diz respeito à atividade empresarial, tem-se no texto constitucional vários excertos nos quais é possível extrair a autorização para a atuação do Estado e dos demais agentes no sentido de firmar ações de transformações econômico-sociais para inclusão social.

É neste contexto que emerge o arsenal previsto no artigo $3^{\circ}$, 170 e 193 da Constituição, que constituíram os princípios gerais da atividade econômica e das disposições gerais de ordem social.

Com efeito, o artigo $3^{\circ}$ exara como objetivos fundamentais do Estado brasileiro: construir uma sociedade livre, justa e solidária, garantir o desenvolvimento nacional.

A seu turno, o artigo 170 da Constituição Federal anuncia os fundamentos da Ordem Econômica, consubstanciados na valorização do trabalho humano e na livre iniciativa. Além disso, aponta a finalidade desta ordem, qual seja, assegurar a todos existência digna, conforme os ditames da justiça social.

Na sequência, o legislador enumerou os princípios regentes da ordem econômica, sendo eles: I - soberania nacional; II - propriedade privada; III - função social da propriedade; IV - livre concorrência; V - defesa do consumidor; VI - defesa do meio ambiente; VII - redução das desigualdades regionais e sociais; VIII - busca do pleno emprego; IX - tratamento favorecido para as empresas de pequeno porte constituídas, sob as leis brasileiras e que tenham sua sede e administração no País.

Esse arcabouço normativo existe porque a Constituição Federal do Brasil trouxe para seu bojo a ordem econômica; ou seja, "constitucionalizou" a racionalidade do mercado.

A concretização dos postulados registrados na Constituição Econômica, como por exemplo os delineados no artigo 170 Constituição Federal do Brasil, se dá por meio de políticas públicas instituídas por normas como a que prevê a isenção fiscal para as microempresas. Assim leciona Eros Grau:

A contemplação, nas nossas Constituições, de um conjunto de normas compreensivo de uma "ordem econômica", ainda que como tal não formalmente referido, é expressiva de marcante transformação que afeta o direito, operada no momento em deixar de meramente prestar-se à harmonização de conflitos e à legitimação do poder, passando a funcionar como instrumento de implementação de políticas públicas[...] $(2008$, p. 15). 
$\mathrm{Na}$ verdade, a Constituição Federal de 1988 caracteriza-se como estatuto marcadamente voltado, tanto do ponto de vista político quanto do jurídico, para a concretização dos direitos fundamentais sociais, apontando para as políticas públicas como instrumentos de ação do Estado contemporâneo brasileiro voltado para tal finalidade.

É nesse contexto que se insere o papel das microempresas na medida em que estas, embora não componham a estrutura estatal, possuem condições de contribuir para promoção do desenvolvimento, de forma que neste mister, contribuem para efetivação da inclusão social no Brasil, concretizando o paradigma constitucional econômico.

E falando em paradigma constitucional econômico, tamanha é a relevância dos pequenos negócios no Brasil que a Constituição Federal elencou como princípio regente da ordem econômica o "tratamento favorecido para as pequenas empresas".

Destarte, o favorecimento às microempresas revela a necessidade de se proteger os organismos microempresariais que possuem menores condições de competitividade em relação às grandes empresas.

Este favorecimento aos pequenos empreendimentos é reafirmado no art. 179 da $\mathrm{CF}$, nos seguintes termos:

A União, os Estados, o Distrito Federal e os Municípios dispensarão às microempresas e às empresas de pequeno porte, assim definidas em lei, tratamento jurídico diferenciado, visando a incentivá-las pela simplificação de suas obrigações administrativas, tributárias, previdenciárias e creditícias, ou pela eliminação ou redução destas por meio de lei. (BRASIL, 2011)

Trata-se de um princípio de isonomia que reconhece as desigualdades que existem na prática. Numa ordem econômica fundada na livre iniciativa, é necessário dispensar tratamento favorecido às pequenas empresas para que estas possam resistir ao mercado competitivo da livre concorrência.

Ferreira Filho (2007, p.65) afirmou que:

Numa era de gigantismo empresarial, a sobrevivência das empresas de pequeno porte é extremamente difícil. São elas, porém, um elemento de equilíbrio e, conseqüentemente, merecem um tratamento especial. 
Além da função social exercida pelas microempresas, já apontado em tópico anterior, o pesquisador Petter (2005, p.38), apresentando justificativa para tal tratamento diferenciado discorreu que:

[...] de outra banda, certo é que o tratamento jurídico favorecido às empresas de pequeno porte tem variados fundamentos a justificar sua inserção dentre os princípios da atividade econômica. Bem examinadas as disposições relativas à ordem econômica no texto constitucional - sem olvidar que ela é parte integrante e indissociável da Constituição vista em sua inteireza - parece mesmo intuitivo que algo deveria ser feito em relação às empresas de pequeno porte. Pois são elas que mais empregam mão-de-obra, o que nos reconduz à valorização do trabalho humano como fundamento da ordem econômica. São elas que menos investimentos necessitam, havendo expansão do desenvolvimento se trilhados os caminhos em face delas abertos. Demais disso, exercem no contexto da economia um papel mais versátil e próximo do consumidor do que o desempenhado por grandes estruturas empresariais. Obtêm sua aprovação no mercado sem intermediação de pesados investimentos publicitários, indutores de hábitos de consumo, em muitos casos, evidentemente supérfluos. Mas também são elas as que mais dificuldades têm para a obtenção de financiamentos junto às instituições financeiras, daí o necessário.

O tratamento jurídico favorecido às empresas de pequeno porte possui variados fundamentos que justificam sua inserção dentre os princípios da atividade econômica. $\mathrm{Na}$ verdade, a busca da preservação da dignidade da pessoa humana, do pleno emprego, entre outros objetivos almejados pela ordem econômica constitucional podem ser melhores obtidos se houver, no Brasil, uma microempresa forte, capaz de sobreviver às intempéries do mercado.

Além de induzir à formalização das atividades econômicas, a preservação da microempresa faz-se necessária para se valorizar o trabalho humano, proteger o consumidor; enfim, promover o que se conhece como desenvolvimento socioeconômico com vistas à dignidade da pessoa humana, que, órbita econômica - é normalmente ignorada, tendo em vista a prevalência da concepção individualista que prevalece na sociedade capitalista.

\section{LITERATURA E DIREITO}

A linguagem estética, objeto primordial da Literatura, e a linguagem jurídica, objeto constitutivo do Direito, são duas linguagens que se complementam na medida em que as duas são a materialização verbal do pensamento e da representação da própria 
vivência do homem. Nesse sentido, os limites entre ficção e realidade se desfazem a ponto de a ficção tornar-se um suporte inerente para a interpretação da realidade.

Interpretar a realidade, no âmbito jurídico, implica em conseguir abstrair os sentidos produzidos a partir de um determinado contexto. Isso requer ao profissional uma habilidade de ler o mundo sob a ótica de vários pontos de vista e uma capacidade de discernir melhor os aspectos resultantes de determinada situação.

Este processo de interpretação da realidade pode ser comparado ao mesmo procedimento do exercício de interpretação de um texto de ficção, com a diferença de que, a partir de uma narrativa ficcional, o leitor aprende mais sobre o mundo que o cerca e apreende outras experiências de vida possíveis representadas no texto literário.

Sobre isto, e também para entender melhor esta questão, é importante, então, discutir sobre a função da literatura. Para o sociólogo e crítico literário Antônio Cândido, no texto A literatura e a formação do homem, a principal função da literatura está relacionada à humanização do homem, ou seja, exprime o homem e depois atua na sua própria formação. Para este intento, o sociólogo nos apresenta três aspectos básicos: a função psicológica, a função formativa e a função social da literatura. (CANDIDO, 1972)

A primeira, a função psicológica, diz respeito à capacidade que a literatura tem de satisfazer a necessidade universal de ficção e de fantasia que pertence ao homem como indivíduo e enquanto grupo. Ela pode estar presente nas formas mais simples (a anedota, a adivinha, o trocadilho, o rifão) e nas mais complexas (narrativas populares, contos folclóricos, lendas e mitos). No nosso estado de civilização, tudo isso resultou nas formas impressas, divulgadas pelo livro, o folheto, o jornal, a revista, o poema, o conto, o romance, etc. e nas formas técnicas modernas, tais como o cinema e a televisão.

Para Cândido, a fantasia nunca é pura porque está estritamente relacionada à realidade e por isso a literatura é umas das modalidades mais ricas. Esta relação entre ficção e realidade, segundo o crítico,

serve para ilustrar em profundidade a função integradora e transformadora da criação literária com relação aos seus pontos de referência na realidade. Ao mesmo tempo, a evocação dessa impregnação profunda mostra como as criações ficcionais e poéticas podem 
atuar de modo sub-consciente e inconsciente, operando uma espécie de inculcamento que não percebemos. (CANDIDO, 1972, p.805).

A segunda função, a formativa, não está vinculada ao processo pedagógico de ensino e aprendizagem, mas na atuação da literatura como instrumento de educação quanto à formação do homem e quanto à contribuição na formação da personalidade no momento em que revela, exprime e reflete as realidades que a ideologia dominante tenta esconder. Nesse sentido,

a literatura pode formar; mas formar não segundo a pedagogia oficial, que costuma vê-la pedagogicamente como um veículo da tríade famosa - o Verdadeiro, o Bom, o Belo, definidos, conforme os interesses dos grupos dominantes, para reforço da sua concepção de vida. Longe de ser um apêndice de instrução moral e cívica, ela age com o impacto indiscriminado da própria vida e educa como ela, - com altos e baixos, luzes e sombras. Ela não corrompe nem edifica, portanto, mas, trazendo livremente em si o que chamamos o bem e o mal, humaniza no sentido profundo, porque faz viver. (CANDIDO, 1972, p.805).

Finalmente, a última função é a questão da literatura como representação de uma dada realidade social e humana. Esta função tem o potencial de oferecer ao leitor um profundo conhecimento do mundo, uma vez que há uma possibilidade de identificação do leitor com o universo narrado. Além de a literatura ser uma forma de expressão, de conhecimento é, também, uma construção artística,

ela significa um tipo de elaboração das sugestões da personalidade e do mundo que possui autonomia de significado; mas que esta autonomia não a desliga das suas fontes de inspiração no real nem anula a sua capacidade de atuar sobre ele. (CANDIDO, 1972, p.806).

Além disso, em outro texto, $O$ direito à literatura, Antônio Candido diz que a literatura dever ser considerada como um direito fundamental, porque tem o papel de oferecer as condições de humanização e, também, reitera a principal função da literatura:

Entendo aqui por humanização (...) o processo que confirma no homem aqueles traços que reputamos essenciais, como o exercício da reflexão, a aquisição do saber, a boa disposição para com o próximo, o afinamento das emoções, a capacidade de penetrar nos problemas da vida, o senso da beleza, a percepção da complexidade do mundo e dos seres, o cultivo do humor. A literatura desenvolve em nós a quota de humanidade na medida em que nos torna mais compreensivos e abertos para a natureza, a sociedade, o semelhante. (CANDIDO, 1995, p.249). 
Dessa forma, a leitura de grandes obras literárias pode transformar o homem em um ser que tem total consciência de si e do mundo em que vive e por isso libertá-lo de um universo alienado e alienante. A leitura é, portanto, um instrumento de emancipação individual e social.

Por este prisma é possível estabelecer e entender melhor a relação existente entre o direito e a literatura. No programa Direto \& Literatura: Realidades ou Ficções, publicado em 16 de dezembro de 2014, o professor e apresentador Dr. Lenio Luiz Streck afirma que "a literatura, não apenas humaniza o direito, mas também pode contribuir para a instituição de uma cultura dos direitos ao tematizar questões como a justiça, a liberdade, a igualdade, a diferença, entre outras.”

Essa fala remete diretamente a tudo aquilo que Antonio Candido discute sobre as funções da literatura em relação à constituição do próprio homem e também sobre a questão de ela viabilizar o acesso à justiça a partir do conhecimento e da reflexão dos direitos humanos representados no texto literário.

A relação entre direito e literatura é, portanto, algo que envolve a construção do conhecimento, não um conhecimento científico a respeito das coisas, mas aquele resultante da vivência de cada indivíduo no meio social tanto do universo real quanto do ficcional, que é caracterizado pela representação da realidade.

O conhecimento empírico adquirido através da leitura de obras literárias é tão - ou talvez mais - relevante quanto aquele que se adquire na vida real. Aliás, este, proporciona ao indivíduo um ponto de vista limitado das circunstâncias vividas e/ou interpretadas. Aquele fornece ao leitor vários pontos de vista, pois o conhecimento do contexto e o seu íntimo relacionamento com a leitura estipulam a alteridade como um processo que permite uma interpretação melhor elaborada do texto.

Nesse sentido, interpretar a realidade através da ficção é, justamente, buscar na verossimilhança do imaginário as respostas às questões que permeiam a vida e que ajudam a compreensão do homem a respeito do mundo que o cerca. No sentido inverso, interpretar a ficção através da realidade é conseguir projetar a própria vivência e o conhecimento aí intrínseco num processo de reconhecimento, identificação e experiência estética do texto. 
Estudar o direito à luz da literatura possibilita um olhar mais abrangente das diversas situações, ou seja, permite analisar os episódios do cotidiano sob outras perspectivas. A literatura nos ensina ler o mundo e, como diz Paulo Freire, é preciso 'ler o mundo para poder transformá-lo’. (FREIRE, 1987)

\section{CEM ANOS DE SOLIDÃO: a (des)construção da representação de uma sociedade utópica}

Cem Anos de Solidão é uma metáfora da América Latina, principalmente da América Hispânica, pois representa, pelo viés dos mitos, das lendas e da imaginação, a construção da nossa identidade enquanto latino-americanos. Ele é um romance que possui uma estrutura diferenciada em virtude da mistura das narrativas históricas e imaginárias da Colômbia (e, por extensão, da América Hispânica e da América Latina) com a história do próprio homem que busca estabelecer a sua identidade. Esta narrativa representa cem anos da família Buendía, que começa, basicamente, quando José Arcadio Buendía funda Macondo.

A problemática que estrutura a narrativa começa com um casamento impróprio, apesar dos sentimentos envolvidos. A família Buendía é constituída pela união de dois primos, Úrsula Iguarán e José Arcadio Buendía. Por apresentarem um parentesco tão próximo, o casal acredita ter cometido o pecado do incesto, o que justifica a angústia da possibilidade de algum tipo de punição divina sobre a família. José Arcadio Buendía e Úrsula Iguarán deram início às sete gerações dos Buendía e à solidão que acompanhou cada geração.

Esse casal teve três filhos: José Arcadio, um rapaz forte e viril; Aureliano, diferente do irmão mais velho, herdou a curiosidade do pai, era mais calmo e introvertido e, finalmente, Amaranta altiva e implacável na personalidade forte e na sua solidão. Além dos três, Rebeca, que foi adotada ainda na infância, era órfã, filha de primos distantes, porém, depois de muito tempo, a família descobre que essa informação de parentesco era falsa e deixou de ser considerada como filha quando se envolveu com 'irmão' mais velho - José Arcadio. 
A narrativa desenvolve-se em torno desta geração, dos seus filhos, netos, bisnetos e trinetos, todos sob o olhar e os cuidados da matriarca Úrsula que sobrevive os cem anos e torna-se o pilar da família. Esta personagem é a única que percebe que as características físicas e psicológicas dos seus descendentes estão associadas à repetição dos nomes, como por exemplo todos os Josés Arcadios são impulsivos e os Aurelianos são curiosos e solitários.

Os Aurelianos têm, ao longo do livro, a missão de estudar e entender os pergaminhos deixados por Melquíades, um cigano, amigo de José Arcadio Buendía, que queria desvendar, entre outras coisas, os mistérios da morte. Os pergaminhos têm um papel bastante relevante na narrativa, pois encerram em si a história dramática da família e são decifrados apenas pelo último Aureliano nos seus momentos finais de vida.

O Coronel Aureliano Buendía se destina a defender os ideais liberais para implantar a justiça social, lutando contra os conservadores, mas seus sonhos se dissolvem com as várias guerras. O sobrinho, que recebeu o seu nome, era chamado Aureliano Segundo, continua com a luta dos mesmos ideais propagados pelo tio. Já, seu irmão, José Arcadio Segundo torna-se funcionário da Companhia Bananeira e luta contra o poder imperialista.

O último Aureliano, Aureliano Babilônia, é uma personagem que sintetiza a história da família, pois possui as características de todos, além disso ele consegue decifrar os misteriosos pergaminhos de Melquíades e

[...] antes de llegar al verso final ya había comprendido que no saldría jamás de esse cuarto, pues estava previsto que la ciudad de los espejos (o los espejismos) sería arrasada por e viento y desterrada de la memoria de los hombres em el instante em que Aureliano Babilonia acabara de descifrar los pergaminos, y que todo lo escrito en ellos era irrepetible desde siempre y para siempre, porque las estirpes condenadas a cien años de soledade no tenían uma segunda oportunidad sobre la tierra. (GARCÍA MÁRQUEZ, 2002, p. 352)

E, assim, o narrador conclui a saga da família Buendía que busca firmar uma identidade em meio à solidão.

Cem anos de solidão não é apenas a história desta família, mas é uma representação artística muito bem desenvolvida da história da Colômbia, da América Latina e até mesmo da história da humanidade, já que, através dos dramas vividos por 
esta família, há aqueles que são universais e retratam a condição humana. Além de apresentar uma reunião de elementos representativos da história, do imaginário e míticos que subsidiados pelo realismo mágico, tornam a leitura fascinante, aproximando o leitor de um mundo, que apesar de ser "mágico", não desfaz a triste e angustiante realidade dos fatos, que representam os reflexos de uma América Latina de constante luta por seus direitos sociais.

O romance inicia-se com a busca de um lugar melhor, um novo mundo, uma terra sem males, sem um governo estabelecido e sem igreja, um lugar onde nem mesmo a morte poderia habitar. Macondo, no decorrer do tempo, transforma-se de um pequeno povoado a uma cidade e essa transformação se dá tanto pela modernização do lugar quanto pelas guerras e lutas que ali acontecem.

José Arcadio Buendía funda o povoado acreditando que o lugar jamais sofreria a interferência de qualquer civilização viciada, mas com as diversas intervenções que aquele povoado recebeu dos visitantes (os ciganos no início, depois pessoas de regiões próximas e estrangeiros), com o aparecimento de uma autoridade civil e de uma igreja, isso não foi possível. Aquele espaço igualitário, onde ninguém tinha nenhum privilégio, onde todos eram iguais, acabou cedendo e foi absorvido pela sociedade que o fundador tanto repudiava.

Melquíades foi o primeiro personagem que desestabiliza a harmonia do ambiente, na medida em que, com suas novidades científicas do velho mundo, desperta a imaginação e a curiosidade de José Arcadio Buendía, que, com ideias delirantes, sonha em promover o progresso em Macondo. Porém, o patriarca sucumbe ao delírio de conseguir alcançar os seus ideais improváveis como separar o ouro da terra com um ímã, reter a memória, instaurar uma sociedade igualitária, capturar uma imagem de Deus para provar a sua existência, entre outras.

Há, portanto, nesta relação entre Melquíades e José Arcadio Buendía uma subversão de valores instaurada, uma vez que o cigano traz para Macondo o conhecimento e a ciência do velho mundo, José Arcadio Buendía acaba enlouquecendo diante das ideias que, a priori, promovem o progresso. A loucura, aqui, revela a representação do embate entre os ideais modernos e progressistas do velho mundo com os ideais utópicos do novo mundo. 
Um elemento bastante relevante que contribui para assegurar a impossibilidade da construção desta sociedade utópica está vinculado à própria estrutura da narrativa, que tem como aporte o realismo mágico, cuja principal característica é relacionar o universo mágico/fantástico à realidade, evidenciando elementos irreais ou estranhos como algo habitual e corriqueiro de forma intuitiva sem nenhuma explicação. Segundo Tania Mara Antonietti-Lopes (2007, p. 14):

[...] o uso atual do termo se refere, estilisticamente, a textos em que o sobrenatural é apresentado como comum, sem causar algum estranhamento. Estruturalmente, a presença do sobrenatural no texto é essencial para a existência do realismo mágico.

Esta corrente literária, também denominada realismo fantástico ou realismo maravilhoso, apesar de ter sido originada na Alemanha, teve maior repercussão na América Hispânica, pois surgiu, aqui, num contexto histórico bastante conturbado, entre as décadas de 60 e 70, período em que os países latino-americanos passavam por processos ditatoriais. Neste momento, o movimento realismo mágico surge como uma forma de reação, que utiliza o elemento mágico como reforço das palavras contrárias aos regimes vigentes.

O realismo mágico evidencia, nesta narrativa, uma cultura de superstição que se contrasta com a cultura tecnológica e científica. A partir deste embate, é possível refletir, então, sobre a construção e a transformação da sociedade, desde os primeiros ideais utópicos - e até mesmo irreais - até a sua modernização influenciada pelo capital estrangeiro.

Um episódio que destaca a ideia de transformação vinculada à influência estrangeira é a chegada da companhia americana "Companhia das Bananeiras". Isso acontece durante a guerra civil quando já se observa alguns sinais de prosperidade, sobretudo na elevação de Macondo à categoria de município.

Os acontecimentos se desenrolam com o cessar do conflito, quando há a chegada efetiva das novas conquistas do mundo moderno. Cita-se, dentre outras novidades, a chegada da energia elétrica, telefone, gramofone, cinema, e, por último, o invento que revolucionou a vida em Macondo: o trem de ferro. Com este meio de transporte, Macondo recebe uma grande quantidade de forasteiros e a cidade cresce em uma 
velocidade estrondosa, sobretudo após a visita de Mr. Hebert, um misterioso senhor americano, que em certa vez, em um jantar na casa dos Buendía, analisava uma banana como se fosse algo muito precioso.

Tempos depois se instala em Macondo a empresa americana "Companhia das Bananeiras" que promove um grande surto industrial na cidade. Juntamente com a chegada do capitalismo percebe-se também o surgimento de uma classe operária organizada. José Arcádio Segundo passa a trabalhar na companhia e, mantendo a tradição militante da família iniciada por Aureliano Buendía, se integra ao movimento sindical, promovendo uma série de revoltas e protestos contra a empresa estrangeira, culminando num massacre de mais de mil pessoas, que ocorreu na madrugada de 6 de dezembro de 1928.

Atento às transformações pelas quais Macondo passa e, principalmente, ao nefasto desfecho deflagrado pela empresa americana (interferência de capital estrangeiro), que ao contrário da expectativa de progresso, trouxe morte e desespero à comunidade, pode se afirmar que os grandes empreendimentos, não necessariamente trazem desenvolvimento: ao contrário, como no caso da Companhia das Bananeiras trouxe revolta e mortes.

Desta feita, faz-se necessário volver atenção para a relevância dos pequenos empreendimentos que, ao contrário dos grandes, podem trazer desenvolvimento e dignidade, quando da franca oportunidade de geração de empregos.

\section{CONCLUSÃO}

As linhas traçadas neste trabalho evidenciaram que estudar o Direito à luz da literatura possibilita um olhar mais abrangente das diversas situações; ou seja, permite analisar os episódios do cotidiano sob outras perspectivas. A literatura ensina ler o mundo para, depois, transformá-lo.

A leitura de grandes obras literárias pode transformar o homem em um ser que tem maior consciência de si e do mundo em que vive e por isso libertá-lo de um universo alienado e alienante. A leitura é, portanto, um instrumento de emancipação individual e social. Daí porque, o estudo do Direito, em necessário cotejo com a 
literatura, possibilita a ampliação da percepção do jurista frente às imbricadas circunstâncias que deve enfrentar.

Assim é que o trabalho se desenvolveu, permeado pelo enredo do romance "Cem Anos de Solidão" cuja narrativa representa cem anos da história da família Buendía, que começa, basicamente, quando José Arcadio Buendía funda Macondo e teve maior destaque a chegada da Companhia das Bananeiras que, no lugar de desenvolvimento, trouxe revolta e mortes, o que possibilitou demonstrar que, como na vida real, crescimento e desenvolvimento não deve ser atrelado apenas aos grandes empreendimentos, ignorando os benefícios advindos com a promoção dos pequenos negócios.

Tanto neste romance, na ficção, quanto na vida real, as grandes empresas estrangeiras têm interesses particulares dissociados dos interesses sociais comuns. Além disso, elas sufocam as pequenas e microempresas, que são responsáveis pelo real crescimento social do país - assim como acontece em Macondo.

Vale pensar, então, a pequena e microempresa como uma alternativa possível para um nivelamento social e econômico, pois concebe-se a pequena empresa como aquela cujo proprietário empenha direta e decisivamente a sua força de trabalho com reduzido quadro de pessoal. Possui pouco capital e baixa renda bruta com relação ao setor onde opera, e não faz parte de grupo econômico ou que esteja interligado com outro empregador.

A discussão em torno das microempresas é legítima à medida que a realidade brasileira revela que este segmento exerce uma função que se sobrepõe à lógica do lucro. Isto, pois, pelo que se expôs no seio deste trabalho, as micros possuem um grande potencial de assimilação da massa desempregada, o que contribui com o crescimento econômico, além de promover um padrão de desenvolvimento mais desconcentrado e eqüitativo nas regiões menos desenvolvidas.

A relevância dos pequenos empreendimentos ganha espaço com o paradigma econômico esposado na Constituição Federal do Brasil, que trouxe para seu bojo um capítulo específico para ordem econômica e, dando destaque aos pequenos negócios, elencou como princípio regente da ordem econômica o "tratamento favorecido para as pequenas empresas". 
Conforme mencionado ao longo deste trabalho, o tratamento jurídico favorecido às empresas de pequeno porte possui variados fundamentos a justificar sua inserção dentre os princípios da atividade econômica. Na verdade, a busca da preservação da dignidade da pessoa humana, do pleno emprego, entre outros objetivos almejados pela ordem econômica constitucional podem ser melhores obtidos se houver, no Brasil, uma microempresa forte, capaz de sobreviver às intempéries do mercado.

\section{REFERÊNCIAS}

ANTONIETTI-LOPES, Tania Mara. O realismo mágico na comunhão estética entre Memorial do Convento e Cem Anos de Solidão. 2007. 92 f. Dissertação (Mestrado em Estudos Literários), Universidade Estadual Paulista, Faculdade de Ciências e Letras de Araraquara, Araraquara, 2007.

BERCOVICI, Gilberto. Constituição econômica e desenvolvimento. São Paulo: Malheiros, 2012.

BOMFIM, Ana Paula Rocha. Comentários ao Estatuto das Microempresas de Pequeno Porte. Rio de Janeiro. 2007

BRAFF, Menalton. Gabriel García Márquez, o mago. Disponível em: http://revistacult.uol.com.br/home/2010/03/gabriel-garcia-marquez-o-mago/ Acesso no dia 03/06/2016.

BRASIL. Constituição (1988). Constituição [da] República Federativa do Brasil. Brasília, DF: Senado Federal.

CANDIDO, Antonio. A literatura e a formação do homem. In: Ciência e cultura. São Paulo. USP, 1972.

Direitos humanos e literatura. In: FESTER, A. C. Ribeiro (org.). São Paulo: Brasiliense, 1989. 1995.

O direito a literatura. In: Vários Escritos. São Paulo: Duas Cidades,

COMPARATO, Fábio Konder. A afirmação histórica dos direitos humanos. 5. ed. São Paulo: Saraiva, 2007.

FERREIRA FILHO. Manoel Gonçalves. Curso de direito constitucional. 33. ed. rev. e atual. São Paulo: Saraiva, 2007.

FREIRE, Paulo. Pedagogia dos oprimidos. 17 ed. Rio de Janeiro: Paz e Terra, 1987. 
GOMES, Sergio Alves. Hermenêutica Constitucional: Um Contributo à Construção do Estado Democrático de Direito. Curitiba: Juruá, 2008.

GRAZZIOTIN, Marcelo Rugeri. Tratamento jurídico diferenciado à pequena empresa no processo do trabalho. São Paulo: LTR, 2004.

SALDÍVAR, Dasso. Gabriel García Márquez. Viagem à semente. Uma biografia. Rio de Janeiro: Record, 2000. Trad. Eric Nepomuceno.

STRECK, Lenio L. Direito \& Literatura: Realidades ou Ficções. Programa exibido em 16/12/2014. Disponível em: https://www.youtube.com/watch?v=k99xKFQ_xUA

RODRIGUES, S. C. Modernidade e pós-modernidade em Gabriel García Márquez. Hispanista. Revista eletrónica de los Hispanistas. Vol. IV - n.16 - enero febrero - marzo - 2004. www.hispanista.com.br/revista/rosto16esp.htm. Acesso em 03/06/2016.

PETTER, Lafayete Josué. Princípios Constitucionais da Ordem Econômica. São Paulo: RT, 2005.

SERVIÇO DE APOIO AS MICRO E PEQUENAS EMPRESAS. Taxa de Sobrevivência das Empresas no Brasil. Coleção Estudos e Pesquisas. Brasília: SEBRAE, 2011b. Disponível em http://www.biblioteca.sebrae.com.br/bds/BDS.nsf/45465B1C66A6772D832579300051 816C. Acessado em: 25 mar 2015

VITULO, Gabriel E. Teorias da democratização frente às democracias latinoamericanas realmente existentes. Opinião Pública, Campinas (SP), v. 12, n. 12, p. 348-377, nov. 2006. 